\title{
Perbandingan Efektivitas Methotrexate pada Pasien Rheumatoid Arthritis (Studi pada Pasien Rawat Jalan di RSUD Ulin Banjarmasin)
}

\author{
Arlina Fauziah', Abdul Rahem², dan Anita Purnamayanti ${ }^{1}$ \\ ${ }^{1}$ Fakultas Farmasi Universitas Surabaya, Surabaya \\ ${ }^{2}$ Fakultas Farmasi Universitas Airlangga, Surabaya \\ Korespondensi: Arlina Fauziah \\ Email: arlinafauziah@gmail.com
}

\begin{abstract}
ABSTRAK: Pasien rawat jalan di Poli Sub Spesialis Rheumatoid Rumah Sakit Daerah Ulin Banjarmasin dalam perjalanan terapi RA mengalami perubahan terapi, yang semula menggunakan methotrexate berubah menjadi menggunakan leflunomide (arava) dan kemudian menjadi azatioprin (imuran) dikarenakan terjadi kekosongan obat RA. Adanya perubahan terapi RA menyebabkan perlu dilakukannya perbandingan efektivitas antara methotrexate dengan pengganti methotrexate. Rancangan penelitian yang digunakan adalah observasional dengan pengambilan data retrospektif. Analisis data dilakukan dengan menggunakan One Way Anova dan Paired $t$-test. Efektivitas terapi pasien RA didasarkan pada aktivitas penyakit, skor Disease Activity Score 28 (DAS28) dan persentase efektivitas. Hasil analisis dengan One Way Anova menunjukkan tidak terdapat perbedaan yang signifikan antara semua kelompok terapi $(\mathrm{P}=0,084, \mathrm{P}>0,05)$. Berdasarkan uji Post Hoc LSD diketahui terdapat perbedaan yang signifikan antara DAS28 methotrexate awal dengan DAS28 imuran akhir $(\mathrm{P}=0,0034, \mathrm{P}<0,05)$ dan antara DAS28 arava akhir dengan DAS28 imuran akhir $(\mathrm{P}=0,049, \mathrm{P}<0,05)$. Pada uji Paired $t$-test terdapat perubahan nilai DAS28 yang signifikan antara methotrexate awal dan akhir, DAS28 arava awal dan akhir serta DAS28 imuran awal dan akhir. Terdapat perbedaan efektivitas methotrexate dengan arava dan imuran dengan arava namun tidak ada perbedaan efektivitas methorexate dengan imuran pada pasien RA rawat jalan di RSUD Ulin Banjarmasin.
\end{abstract}

Kata Kunci: Rheumatoid Arthritis; efektivitas; methotrexate; arava; imuran

ABSTRACT: The occurrence of methotrexate drug shortage at Ulin Banjarmasin Regional Hospital caused a change of Rheumatoid Arthriris (RA) therapy in outpatients, which was originally used methotrexate turned into using leflunomide (arava) and later on azatioprine (imuran). It was necessary to analyze the efficacy between methotrexate with methotrexate replacement therapy. Design of the study was an observational research with retrospective retrieval data. Data analysis using One Way Anova and Paired t-test. The efficacy of patient therapy RA analyzed from the Disease Activity Score 28 (DAS28) and efficacy percentage. The results of One Way Anova analysis showed no significant difference between all treatment groups $(P>0.05)$. From a Post Hoc LSD test it was found that there were significant differences between the initial DAS28 methotrexate with the final DAS28 imuran $(P=0.0034)$, and between the final DAS28 arava with the final DAS28 imuran $(P=0.049)$. In the Paired t-test there were significant on mean differences between the initial and final DAS28 methotrexate, the initial and final DAS28 arava, and the initial and final DAS28 imuran. There was a difference in the efficacy of methotrexate with arava and imuran with arava but there was no differences in the efficacy of methorexate with imuran in outpatient RA patients in RSUD Ulin Banjarmasin.

Keywords: Rheumatoid Arthritis; efficacy; methotrexate; arava; imuran. 


\section{Pendahuluan}

Rheumatoid Arthritis (RA) merupakan penyakit peradangan sendi kronis yang ditandai dengan peradangan, nyeri, kekakuan dan kerusakan sendi progresif. Meskipun dapat menyerang pada segala usia, tingkat prevalensi meningkat secara progresif dan tingkat kejadian terjadi lebih tinggi pada wanita dibandingkan pria. Selain dapat menyebabkan peningkatan morbiditas dan mortalitas, orang dengan RA dapat mengalami kerusakan sendi permanen serta cacat fungsional yang berat dan mengarah pada penurunan kualitas hidup penderita [1].

Penderita penyakit Rheumatoid Arthritis (RA) mengalami berbagai macam gejala yang berdampak negatif terhadap kualitas hidup. Pengobatan yang dilakukan saat ini tidak hanya bertujuan mencegah atau berusaha menyembuhkan RA, tujuan pengobatan juga untuk mengurangi akibat yang ditimbulkan penyakit RA dalam hidup pasien dengan meningkatkan kualitas hidup dan mengurangi kecacatan [2].

Pada Poli Sub Spesialis Rumah Sakit Umum Daerah Ulin Banjarmasin, data yang didapat dari jumlah kunjungan pasien RA di Poli Sub Spesialis Rheumatoid dari tahun 2013 (16,81\%), tahun 2014 (36,07\%), tahun 2015 (34,37\%) cenderung meningkat walaupun terjadi penurunan sedikit di tahun 2015, tetapi dengan peningkatan jumlah pasien. Pasien RA pada Poli Sub Spesialis Rheumatoid berasal dari berbagai usia dan cenderung lebih banyak wanita dan usia lanjut. Pasien dengan RA di RSUD Ulin mengalami peningkatan setelah dibukanya Poli Sub Spesialis Rheumatoid, dimana pengobatan untuk pasien RA menjadi lebih terfokus [3].

Tahap pengobatan yang sesuai dengan konsep mengurangi nyeri dan mencegah kerusakan sendi digunakan obat-obatan konvensional dalam pengobatan RA. Disease Modifying Anti Rheumatic Drugs (DMARD) menjadi pilihan pertama dalam terapi RA. DMARD memiliki potensi untuk mengurangi kerusakan sendi, mempertahankan integritas dan fungsi sendi dan meningkatkan produktivitas pasien RA. Penggunaan DMARD sejak awal dapat memberikan hasil yang lebih baik dan menurunkan angka mortalitas. Penggunaan DMARD membutuhkan waktu lebih lama dalam perbaikan gejala dibandingkan dengan Non Steroid Anti Inflammatory Drugs (NSAID). Namun NSAID tidak berpengaruh banyak terhadap progresivitas penyakit [4].

Obat-obat DMARD yang sering digunakan dalam terapi RA adalah methotrexate, sulfasalazin, leflunomide, klorokuin, siklosporin, dan azatioprin. Dalam guideline European League Against Rheumatism (EULAR) 2013 methotrexate direkomendasikan sebagai terapi lini pertama dalam penanganan RA. Methotrexate dianggap sebagai obat penting dalam pengobatan RA dan methotrexate direkomendasikan sebagai DMARD pertama di awal pengobatan RA [5]. Methotrexate juga tercantum dalam Formularium Nasional untuk pasien BPJS [6].

Terapi RA memerlukan pemantauan aktivitas penyakit, baik melalui evaluasi klinis maupun laboratorium dengan menggunakan skor Disease Activity Score (DAS28). Pemantauan ini diperlukan untuk meningkatkan pengobatan supaya penyakit lebih terkendali atau bila ada perubahan terapi [7]. DAS28 direkomendasikan oleh ACR dalam pengukuran aktifitas penyakit RA karena merupakan cerminan aktifitas penyakit yang akurat, sensitif terhadap perubahan, dapat membedakan baik antara aktifitas penyakit rendah, sedang dan tinggi. DAS28 memiliki kriteria remisi dan layak digunakan dalam praktek klinis [8].

Pasien rawat jalan di Poli Sub Spesialis Rheumatoid Rumah Sakit Daerah Ulin Banjarmasin dalam perjalanan terapi RA mengalami perubahan terapi, yang semula menggunakan methotrexate berubah menjadi menggunakan leflunomide (arava) dan juga azatioprin (imuran), yang dikarenakan terjadi kekosongan methotrexate dan kemudian disusul dengan kekosongan leflunomide. Kekosongan terjadi dari bulan September 2016 sampai dengan April 2017, yang disebabkan karena methotrexate yang awalnya tercantum dalam e katalog tidak tercantum lagi 
dan kekosongan dari distributor yang dikarenakan kekosongan bahan baku. Kekosongan leflunomide dikarenakan keterlambatan pengiriman dari pabrikan ke pihak distributor, sehingga terjadi kekosongan di Rumah Sakit.

Obat yang digunakan dalam terapi RA meliputi DMARD, agen biologik, kortikosteroid dan obat anti inflamasi non steroid. Jika target pengobatan tidak dicapai dengan strategi DMARD pertama, dengan tidak adanya faktor prognostik yang buruk, diubahlah strategi dengan DMARD yang lain. Bila ada faktor prognostik yang buruk, penambahan bDMARD harus dipertimbangkan. Dalam penelitian terdahulu dengan membandingkan terapi Methotrexate dengan leflunomide, methotrexate menunjukkan hasil yang terbaik dibanding leflunomide $[9,10,11]$. Penelitian dengan memberikan monoterapi methotrexate, kombinasi methotrexate-prednison, azathioprin-prednison dan methotrexate-infiximib menunjukkan kombinasi azathioprin-prednison dan kombinasi methotrexate-infiximab secara klinis maupun dilihat dari hasil radiografi lebih baik dari monoterapi methotrexate [12].

Belum terdapat penelitian terdahulu yang membandingkan methotrexate, leflunomide, dan azathioprin secara berurutan. Melalui penelitian yang membandingkan pengobatan RA dengan penggunaan terapi secara berurutan akan dapat diketahui urutan yang efektif dalam strategi pengobatan RA. Namun penelitian dengan penggunaan terapi secara berurutan kurang lazim dilakukan mengingat etika dan kondisi pasien.

Dengan adanya perubahan terapi yang dikarenakan oleh kekosongan methotrexate yang disusul kekosongan leflunomide, perlu dilakukan perbandingan efektivitas methotrexate dengan pengganti methotrexate. Dengan diketahuinya perbandingan efektivitas dari beberapa terapi maka akan dapat dilakukan perbaikan atau usaha dalam pengadaan obat yang diperlukan namun terdapat kendala dalam pengadaannya, misal melalui Pusat Rujukan Obat Nasional (PRON) yang dikoordinir oleh Kemenkes.

\section{Metode}

Rancangan penelitian yang digunakan pada penelitian ini adalah observasional dengan pengambilan data retrospektif. Analisis data dengan menggunakan One Way Anova dan Paired t-test. Efektivitas terapi pasien RA didasarkan pada aktivitas penyakit, Disease Activity Score 28 (DAS28), dan persentase efektivitas.

Sampel pada penelitian ini adalah bagian dari populasi yang memenuhi kriteria inklusi dan eksklusi yang diambil dengan metode total sampling. Besar sampel ditentukan berdasarkan lamanya periode penelitian. Penelitian dilakukan selama bulan Juli 2016 - Agustus 2017.

Variabel bebas dalam penelitian ini adalah jenis terapi RA meliputi methotrexate dan pengganti methotrexate (leflunomide (arava) dan azathioprin (imuran)). Variabel tergantung dalam penelitian ini adalah efektivitas methotrexate dan pengganti methotrexate yang dinilai dari skor DAS 28.

Pengumpulan data dilakukan secara retrospektif dengan mengambil data MR pasien RA Poli Sub Spesialis Rheumatoid Rumah Sakit Umum Daerah Ulin Banjarmasin yang akan digunakan sebagai sampel penelitian. Analisis data dengan melihat skoring DAS28 dengan menggunakan rumus atau dengan program kalkulator yang dapat diakses melalui internet/aplikasi. Data-data yang didapat ditulis pada kolom yang telah disediakan.

\section{Hasil}

\subsection{Data karakteristik sampel}

Dalam penelitian ini didapat 18 sampel yang setelah melalui proses inklusi dan eksklusi. Data yang dieksklusi adalah data yang tidak memenuhi kriteria yaitu data MR pasien tidak lengkap, pasien tidak meneruskan pengobatan (putus obat), pasien dengan keganasan, pasien yang menggunakan terapi tidak sesuai dengan kriteria yang ditetapkan yaitu yang dimulai dari methotrexate, arava, kemudian imuran.

Ada 18 sampel penelitian masing-masing 
mendapatkan terapi methotrexate, arava kemudian imuran. Pengukuran skor DAS28 dilakukan setelah 3-4 bulan penggunaan masing-masing terapi. Masing-masing DAS28 dari sampel dihitung dengan kalkulator DAS28 dengan komponen yang diukur meliputi jumlah sendi yang sakit, jumlah sendi yang bengkak, VAS, dan nilai ESR.

Data karakteristik awal sampel pada penelitian ini berupa umur dan jenis kelamin. Rentang usia sampel yang masuk dalam penelitian ini adalah 19-84 tahun, dimana sampel yang terbanyak berumur antara 41-62 tahun dan yang lebih banyak adalah wanita. Data karakteristik sampel pasien RA pada penelitian ini berupa umur dan jenis kelamin. Data karakteristik sampel dapat dilihat pada tabel 1. Dari tabel 1 terlihat bahwa wanita lebih banyak yang mengalami RA dibanding laki-laki dan usia yang terbanyak pada penelitian ini adalah pada rentang usia 41 tahun sampai 62 tahun.

\subsection{Perhitungan DAS28}

Tabel 1. Data karakteristik pasien berdasarkan kelompok usia dan jenis kelamin

\begin{tabular}{|c|c|c|c|}
\hline \multirow{2}{*}{$\begin{array}{l}\text { Kelompok usia } \\
\text { (tahun) }\end{array}$} & \multicolumn{2}{|c|}{ Jenis kelamin $(n=18)$} & \multirow[t]{2}{*}{ Frekuensi } \\
\hline & Laki-laki & Perempuan & \\
\hline $19-29$ & 0 & 3 & $3(16,67 \%)$ \\
\hline $30-40$ & 0 & 1 & $1(5,56 \%)$ \\
\hline $41-51$ & 3 & 2 & $5(27,78 \%)$ \\
\hline $52-62$ & 1 & 5 & $6(33,33 \%)$ \\
\hline $63-73$ & 0 & 1 & $1(5,56 \%)$ \\
\hline $74-84$ & 1 & 1 & $2(11,11 \%)$ \\
\hline Total & $5(27,78 \%)$ & $13(72,22 \%)$ & $18(100 \%)$ \\
\hline
\end{tabular}

Tabel 2. Rerata DAS28 berdasarkan kelompok obat RA

\begin{tabular}{ll}
\hline Kelompok obat & Rata-rata DAS28 \\
\hline Methotrexate awal & 5,75 \\
Methotrexate akhir & 5,15 \\
Arava Akhir & 5,69 \\
Imuran Akhir & 4,95 \\
\hline
\end{tabular}

perbedaan yang signifikan antara DAS28 metho-
trexate awal dengan DAS28 imuran akhir (P =

perbedaan yang signifikan antara DAS28 metho-
trexate awal dengan DAS28 imuran akhir (P =
Dari perhitungan DAS28 maka didapat data DAS28 methotrexate awal, DAS28 methotrexate akhir, DAS28 arava akhir dan DAS28 imuran akhir. Rata-rata dari masing-masing DAS28 sebagai berikut: perubahan DAS28 methotrexate awal dengan DAS28 methotrexate akhir minimal -0,53 dan maksimal 2,19; perubahan DAS28 methotrexate akhir dengan DAS28 arava akhir minimal -2,09 dan maksimal 1,11 dan perubahan DAS28 arava akhir dengan DAS28 imuran akhir minimal -0,52 dan maksimal 3,10. Rerata DAS28 berdasarkan kelompok obat RA dapat dilihat pada tabel 2.

\subsection{Analisis Statistik}

Output One Way Anova menunjukkan bahwa nilai F hitung adalah sebesar 2,309 dengan sign 0,084, dengan demikian dapat disimpulkan bahwa $\mathrm{H}_{0}$ diterima atau tidak terdapat perbedaan yang signifikan antara semua kelompok terapi. Selanjutnya dari uji Post Hoc LSD dapat disimpulkan bahwa secara keseluruhan tidak ada perbedaan yang signifikan $(P>0,05)$, namun terdapat

0,0034) dan antara DAS28 arava akhir dengan DAS28 imuran akhir $(\mathrm{P}=0,049)$. 
Analisis dengan Paired t-test yang membandingkan DAS28 masing-masing terapi DAS28 awal dan DAS28 akhir. Methotrexate dan imuran menunjukkan penurunan skor DAS28 yang signifikan, yang berarti kondisi RA membaik. Pada arava menunjukkan adanya kenaikan skor DAS28 yang signifikan, yang berarti kondisi RA memburuk.

\subsection{Persentase efektivitas}

Efektivitas terapi pasien RA dilihat dari adanya penurunan Disease Activity Score 28 (DAS28) atau adanya perubahan aktivitas penyakit. Pada terapi dengan methotrexate ada 12 sampel yang mengalami penurunan nilai DAS28, dapat dikatakan pada saat terapi dengan methotrexate terlihat efektifitasnya pada 12 sampel. Pada 6 sampel lainnya terapi dengan methotrexate tidak efektif dimana terlihat peningkatan nilai DAS28.

Pada terapi dengan arava ada 4 sampel yang mengalami penurunan nilai DAS28, dapat dikatakan pada saat terapi dengan arava terlihat efektifitasnya pada 4 sampel. Pada 14 sampel lainnya terapi dengan arava tidak efektif dimana terlihat peningkatan nilai DAS28.

Pada terapi dengan imuran ada 14 sampel yang mengalami penurunan nilai DAS28, dapat dikatakan pada saat terapi dengan imuran terlihat efektifitasnya pada 14 sampel. Pada 4 sampel lainnya terapi dengan imuran tidak efektif dimana terlihat peningkatan nilai DAS28.

Output One Way Anova untuk persentase efektivitas menunjukkan bahwa nilai $\mathrm{F}$ hitung adalah sebesar 12,532 dengan sign 0,000, dengan demikian dapat disimpulkan bahwa $\mathrm{H}_{1}$ diterima atau terdapat perbedaan yang signifikan pada persentase efektivitas antara semua kelompok terapi. Selanjutnya dilakukan uji Post Hoc LSD, diketahui ada perbedaan antar kelompok. Dapat disimpulkan bahwa secara keseluruhan ada perbedaan yang signifikan $(P=0,000)$ dan terdapat perbedaan yang signifikan antara persentase efektivitas methotrexate dengan persentase efek- tivitas arava $(P=0,000)$ dan antara persentase efektivitas imuran dengan persentase efektivitas arava $(\mathrm{P}=0,000)$.

\section{Pembahasan}

Data karakteristik awal sampel pada penelitian ini berupa umur dan jenis kelamin. Rentang usia sampel yang masuk dalam penelitian ini adalah 19-84 tahun, dimana sampel yang terbanyak berumur antara 41-62 tahun dan yang lebih banyak adalah wanita. Pada beberapa literatur lain juga ditemukan rasio pada pasien dengan $\mathrm{RA}$ perempuan lebih tinggi dibandingkan laki-laki $(3,2: 1)$, dan ada yang menyatakan $85 \%$ adalah wanita, dengan usia rata-rata saat pemeriksaan adalah 52,6 tahun $[13,14]$.

Pengukuran efektivitas methotrexate dan pengganti methotrexate pada penelitian ini dilihat dari adanya penurunan skor DAS28 dan adanya perubahan aktivitas penyakit RA pada sampel yang diteliti. Pengukuran DAS28 dilakukan setelah 3-4 bulan penggunaan terapi, dengan urutan penggunaan terapi yang dimulai dengan methotrexate kemudian arava diikuti imuran. Urutan bisa mempengaruhi hasil penelitian tergantung dari karakteristik masing-masing terapi.

Pengukuran perbedaan efektivitas antara methotrexate, arava, dan imuran pada pasien RA rawat jalan di RSUD Ulin Banjarmasin dengan uji One Way Anova secara keseluruhan tidak terdapat perbedaan yang signifikan. Setelah dilakukan uji lebih lanjut dengan Post Hoc LSD diketahui walaupun perbedaan antar kelompok terapi secara keseluruhan tidak ada perbedaan yang signifikan, namun terdapat perbedaan yang signifikan antara DAS28 methotrexate awal dengan DAS28 arava akhir dan antara DAS28 arava akhir dengan DAS28 imuran akhir.

Dalam penelitian ini didapat efektivitas methotrexate dengan imuran tidak berbeda signifikan dalam penurunan skor DAS28. Tetapi pada arava terdapat peningkatan skor DAS28 yang bisa di- 
simpulkan efektivitas methotrexate dan imuran lebih baik dari arava. Terapi dengan arava pada literatur disebutkan untuk pengobatan RA diberikan dengan loading dose namun pada penelitian ini arava tidak diberikan loading dose melainkan diberikan dengan dosis $20 \mathrm{mg}$ perhari. Hal ini yang diduga dapat menyebabkan terjadinya peningkatan skor DAS28. Tidak terdapat penelitian sebelumnya yang memberikan methotrexate yang kemudian diganti menjadi leflunomide lalu diganti lagi dengan azathioprin secara berurutan.

Hasil yang didapat dalam setiap penelitian dapat berbeda dikarenakan metode yang digunakan berbeda, sampel berbeda, dan waktu pelaksanaan penelitian yang berbeda. Penelitian yang dilakukan ini merupakan bagian dari pemantauan terapi RA, dimana pemantauan terapi RA perlu dilakukan apabila ada perubahan terapi RA yang disebabkan terapi yang diberikan sebelumnya setelah kurun waktu tertentu tidak menyebabkan perubahan aktivitas penyakit yang lebih baik.

Dalam penelitian ini pemantauan terapi RA dilakukan karena ada kekosongan obat methotrexate yang disusul dengan kekosongan arava, sehingga waktu yang diperlukan untuk suatu obat memberikan efek terapi bisa belum terlihat maksimal walaupun di beberapa literatur disebutkan efek methotrexate dapat dilihat setelah 3 bulan terapi.

Pada penelitian ini tidak menganalisis pengaruh urutan pemberian terapi. Sampel yang mendapat terapi obat secara berurutan juga mempengaruhi hasil efektivitas terapi RA, sehingga seharusnya perlu dianalisis lebih lanjut apakah urutan terapi yang tepat untuk terapi RA sehingga tujuan pengobatan dari RA tercapai.

Dari analisis pola perubahan terapi aktivitas Penyakit Aktif (PA), aktivitas Penyakit Sedang (PS) dan Remisi (R) didapat beberapa pola yaitu:
1. PA - PS - PA - PS (1 sampel)
2. $P A-P S-P A-R(1$ sampel)
3. $\mathrm{PA}$ - PA - PA - PA (8 sampel)

4. $\quad$ PS - PS - PS - PS (3 sampel)

5. $\quad \mathrm{PS}$ - PS - PA - PA (2 sampel)

6. $\quad \mathrm{PS}$ - PS - PS - PR (1 sampel)

7. $\mathrm{PA}$ - PA - PA - PS (2 sampel)

Diketahui bahwa ada 1 sampel yang mengalami remisi dan 1 sampel dengan aktivitas penyakit rendah. Efektivitas terapi RA juga dapat dilihat dari penurunan aktivitas penyakitnya yaitu pada pola 1 dan pola 7 dimana aktivitas penyakit berubah yang semula aktivitas penyakit aktif menjadi aktivitas penyakit sedang.

Pada pola di atas juga diketahui perubahan aktivitas penyakit belum didapat pola 3 karena sampel yang awalnya dengan penyakit aktif setelah akhir pengobatan dalam kurun penelitian ini aktivitas penyakit RA masih aktif. Hal ini dapat disebabkan waktu pengambilan data pada penelitian ini kurang lama.

Pengukuran persentase efektivitas terapi RA pada masing masing terapi dihitung dengan membandingkan persentase penurunan skor DAS28 terhadap persentase penurunan skor DAS28 terhadap target remisi (DAS28 $<2,6$ ). Persentase efektivitas terapi RA antara methotrexate, arava, dan imuran dilakukan uji One Way Anova secara keseluruhan terdapat perbedaan yang signifikan. Setelah dilakukan uji Post Hoc LSD terdapat perbedaan yang signifikan antara persentase efektivitas methotrexate dengan persentase efektivitas arava dan antara persentase efektivitas imuran dengan persentase efektivitas arava.

\section{Kesimpulan}

Terdapat perbedaan efektivitas methotrexate dengan arava dan imuran dengan arava namun tidak ada perbedaan efektivitas methorexate dengan imuran berdasarkan perubahan aktivitas penyakit, skor DAS28 dan persentase efektivitas pada pasien RA rawat jalan di RSUD Ulin Banjarmasin.

\section{Daftar pustaka}


1. Bykerk VP, Akhavan P, Hazlewood GS, et al. Canadian Rheumatology Association recommendations for pharmacological management of rheumatoid arthritis with traditional and biologic disease-modifying antirheumatic drugs. J Rheumatol. 2012;39(8):1559-82.

2. Rzeszutek M, Oniszczenko W, Kwiatkowska B. Stress coping strategies, spirituality, social support and posttraumatic growth in a Polish sample of rheumatoid arthritis patients. Psychol Health Med. 2017;(January):1-7.

3. Laporan Kunjungan Poli Sub Spesialis RSUD Ulin Banjarmasin. 2015-2017. (Tidak dipublikasikan).

4. DiPiro JT, Talbert RL, Yee GC, Gary RM, Barbara GW PM. Pharmacotherapy: A Pathophysiologic Approach, 9e | AccessPharmacy | McGrawHill Medical. 2014. https://accesspharmacy. mhmedical.com/book.aspx?bookid=689.

5. Smolen JS, Landewe R, Bijlsma J, Burmester G, Chatzidionysiou K. EULAR recommendations for the management of rheumatoid arthritis with synthetic and biological disease-modifying antirheumatic drugs: 2016 update. BMJ Publ Gr.

6. Kemenkes. Formularium Nasional. Indonesia; 2013:35.

7. Divisi Reumatologi DIPDFJP. Rekomendasi Perhimpunan Reumatologi Indonesia Diagnosis dan pengelolaan Artritis Reumatoid. 2014:1-22.

8. Anderson J, Caplan L, Yazdany J, Robbins ML,
Neogi T, Michaud K. Rheumatoid Arthritis Disease Activity Measures: American College of Rheumatology Recommendations for Use Clinical Practice. Arthritis Care Res. 2012;64(5):640-7.

9. Aletaha D, Stamm T, Kapral T, et al. Survival and effectiveness of leflunomide compared with methotrexate and sulfasalazine in rheumatoid arthritis: a matched observational study. Ann Rheum Dis. 2003;62(10):944-51.

10. Favalli EG, Bugatti S, Biggioggero M, Caporali R. Treatment Comparison in Rheumatoid Arthritis Head to Head Trials and Innovative Study Designs. BioMed Research International; 2014.

11. Li R, Zhao JX, Su Y, et al. High remission and low relapse with prolonged intensive DMARD therapy in rheumatoid arthritis (PRINT): A multicenter randomized clinical trial. Med. 2016;95(28).

12. Graudal N, Jurgen G. Similar Effects of DiseaseModifying Antirheumatic Drugs, Glucocorticoids, and Biologic Agents on Radiographic Progression in Rheumatoid Arthritis. Arthritis \& Rheumatology. 2010;62(10):2852-63.

13. Schneider $M$, Krüger $K$. Rheumatoide arthritis - Frühdiagnose und krankheitskontrolle. Dtsch Arztebl Int. 2013;110(27-28):477-84.

14. Afriyanti FN. Tingkat Pengetahuan Lansia Tentang Penyakit Rheumatoid Arthtritis di Panti Sosial Tresna Werdha (PSTW) Budi Mulia 1 Cipayung Jakarta Tahun 2009;2011. 